\title{
Safety and Feasibility of Transradial Approach for Coronary Artery Bypass Graft Intervention
}

\author{
Hemanta I Gomes, ${ }^{1}$ C M Shaheen Kabir, ${ }^{2}$ Saidur Rahman Khan, ${ }^{3}$ M G Azam, ${ }^{4}$ Syed Mosfiqur Rahman ${ }^{5}$
}

\begin{abstract}
Background \& Objective: To compare the safety and feasibility of using radial versus femoral access during coronary artery intervention of patients who had previously undergone coronary artery bypass graft (CABG) surgery.

Methods: The study was conducted in Ibrahim Cardiac Hospital \& Research Institute (ICHRI), Dhaka from January 2013 to December 2015. During the period a total of 380 patients with past CABG surgery underwent diagnostic coronary angiogram (CAG) and percutaneous coronary intervention (PCI) at our institution. We retrospectively evaluated 98 consecutive patients who underwent graft intervention via the transradial (TRA, $n=54)$ or transfemoral approach (TFA, $n=44$ ) route. Baseline clinical characteristics, angiographic characteristics and complications between the two study groups were observed.

Result: The baseline clinical characteristics between the two study groups were similar. No significant difference was observed in terms of angiographic characteristics between the two groups. Contrast volume in between the groups was pretty similar ( $p=0.267)$. Procedure time $(40 \pm 20 \mathrm{~min}$ vs. $41 \pm 7 \mathrm{~min}, p=0.36)$ and fluoroscopy time $(11.1 \pm 6.5 \mathrm{~min}$ vs. $12.5 \pm 8.7 \mathrm{~min}, \mathrm{p}=0.19)$ were almost similar in both access for graft intervention. All PCI attempts were successful in both groups. Stent deployment was significantly more common in the TR access group. No significant difference was observed between the groups in terms of target vessel intervention. There was no major adverse cardiac event during hospitalization. However, the vascular access site complications were significantly lower $(p=0.003)$ in the TRA group.
\end{abstract}

Conclusion: The TRA for coronary artery bypass graft intervention is safe and feasible.

Key words: Transfemoral, Transradial, Coronary Artery Bypass Graft intervention etc.

\section{INTRODUCTION:}

Among patients undergoing coronary procedures, patients with coronary artery bypass grafts (CABG) represent an important, high risk subgroup. Coronary angiography (CAG) via transradial approach (TRA) has gained growing acceptance and operator preference in recent years, based on a reduction in vascular complications and mortality when compared with transfemoral approach (TFA). ${ }^{1,2}$ However, it has been suggested that these advantages come at the cost of increased procedure time and fluoroscopy dose. ${ }^{3-5}$

\section{Authors' information:}

'Dr. Hemanta I Gomes, D-Card, Assistant Professor\& Associate Consultant in Cardiology, Ibrahim Cardiac Hospital \& Research Institute, Dhaka-1000, Bangladesh.

2 Dr. C M Shaheen Kabir, MD, FSCAI, FACC, Associate Professor \& Consultant in Cardiology, Ibrahim Cardiac Hospital \& Research Institute, Dhaka-1000, Bangladesh.

${ }^{3}$ Dr. Saidur Rahman Khan, MD, PhD, FACC, Professor \& Senior Consultant in Cardiology, Ibrahim Cardiac Hospital \& Research Institute, Dhaka-1000, Bangladesh.

${ }^{4}$ Dr. M G Azam, MD, FSCAl, Professor of Cardiology, National Institute of Cardiovascular Diseases, Dhaka-1207, Bangladesh.

${ }^{5}$ Dr. Syed Mosfiqur Rahman, FCPS, Registrar in Cardiac Surgery, Ibrahim Cardiac Hospital \& Research Institute, Dhaka-1000, Bangladesh.

Correspondence: Dr. C M Shaheen Kabir, Phone: +8801817578389 E-mail: skabir67@yahoo.com 
Considering the significant morbidity and mortality benefits, increased patient preference and cost effectiveness, the European Society of Cardiology now advocates TRA as the default access route for CAG. ${ }^{6-8}$ Studies comparing access route preference mainly involve native coronary vessel angiograms, mostly excluding patients post CABG surgery. ${ }^{9}$ Although there is insufficient evidence to advocate TRA for patients with coronary grafts, both native arteries and grafts, including the left internal mammary artery, can be commonly studied from the left radial artery. We sought to compare safety and feasibility using radial versus femoral access during coronary intervention of patients who had previously undergone CABG surgery.

\section{METHODS:}

A retrospective analysis was undertaken of demographic, clinical and procedural variables of all patients with past CABG surgery who underwent diagnostic CAG and percutaneous coronary intervention (PCI) at Ibrahim Cardiac Hospital \& Research Institute (ICHRI) between January 2013 and December 2015. The study protocol was approved by the Ethics Committee of ICHRI. Choice of TRA or TFA was at the consultant/operator's discretion. During the period a total of 380 patients with past CABG surgery underwent diagnostic coronary angiogram (CAG) and percutaneous coronary intervention (PCI) at our institution. TRA was accessed in 54 cases, while TFA was accessed in 44 cases. For TRA catheterization, a satisfactory Allen's test result was confirmed. Cardiology fellows were equally involved in both TRA and TFA cases during the study and were supervised throughout, with prompt consultant intervention if access attempts failed twice or difficulties arose during the procedure. After subcutaneous local anesthesia, the radial artery was cannulated with a $6 \mathrm{Fr}$ Radifocus introducer sheath (Terumo Corporation). Then, 5000 $\mathrm{U}$ of intraarterial unfractionated heparin and $2.5 \mathrm{mg}$ of intraarterial verapamil were administered. Radial hemostasis was subsequently obtained using digital pressure. Femoral arteries were cannulated similarly with $7 \mathrm{Fr}$ sheaths and hemostasis was later obtained by digital pressure. Contrast volume was the primary endpoint whereas the procedural and fluoroscopy time, procedural success (less than $50 \%$ residual stenosis with antegrade TIMI flow grade 3 at the end of the procedure), access site major bleeding, pre discharge major adverse cardiovascular events (MACE) were the secondary endpoint both for CAG and PCI.

Statistical analyses were performed using Statistical Package for Social Sciences(SPSS), version 20. Continuous variables were presented as mean with SD and categorical variables as counts and percentages. While continuous data were compared between groups using Unpaired t-Test, categorical data were compared between groups using Chi-square $\left(\chi^{2}\right)$ or Fisher's Exact Test. Level of significance was set at $5 \%$ and differences between groups were considered statistically significant when p-value was observed to be $<0.05$.

\section{RESULTS:}

There was no significant difference between TRA and TFA in terms of age, gender, BMI, prior MI, prior PCI and diabetes and all other clinical variables of interest. The mean LVEF was also similar between the groups (Table I). Compared with femoral access, diagnostic CAG in TRA required relatively low contrast volume though the difference was not statistically significant $(70 \pm 34$ vs. $72 \pm 40 \mathrm{ml}$, $p=0.267)$. Procedure time ( $25.2 \pm 10.7$ vs. $26.9 \pm 6.8$ min, $p=0.735)$ and fluoroscopy time $(10.7 \pm 5.5$ vs. $9.5 \pm 4.7 \mathrm{~min}, \mathrm{p}=0.424$ ) were almost similar in both access groups for CAG (Table II). No significant difference was found between TRA and TFA with regard to mean number of grafts used and number of lesions treated ( $p>0.05$ in each case) (Table III \& IV). Stent was deployed in more than $90 \%$ cases in both groups $(p<0.05)$. The mean diameter of the stents was larger in the TFA group, but no significant difference was found with regard to mean number of stents used (Table IV).

All PCI attempts were successful in both groups. There was no major adverse cardiac event during hospitalization. However, TRA was associated with significantly lower rate of vascular complications 
$(p=0.003)$ and less access site-related bleeding $(p=0.404)$. Major complications were limited to 2 cases of acute renal failure and 1 case of cerebrovascular event in the TFA group, and 1 case of acute renal failure in the TRA group. Three failed cases of TRA necessitated crossover to TFA-one due to the spasm of the radial artery and two others due to the tortuosities of the upper arms (Table V).

\begin{tabular}{|c|c|c|c|}
\hline \multirow{2}{*}{$\begin{array}{l}\text { Baseline } \\
\text { characteristics }\end{array}$} & \multicolumn{2}{|c|}{ Group } & \multirow[b]{2}{*}{$\mathrm{p}$-value } \\
\hline & $\begin{array}{l}\text { Radial access } \\
\quad(n=155)\end{array}$ & $\begin{array}{c}\text { Femoral access } \\
(n=225)\end{array}$ & \\
\hline \multicolumn{4}{|l|}{ Demography } \\
\hline Age \# (years) & $60.7 \pm 8.9$ & $60.3 \pm 8.2$ & 0.555 \\
\hline Men* & $129(83.2)$ & $181(80.4)$ & 0.089 \\
\hline BMI\# (kg/m2) & $26.1 \pm 4.4$ & $25.7 \pm 3.4$ & 0.479 \\
\hline \multicolumn{4}{|c|}{ Clinical presentation } \\
\hline$S A^{*}$ & 75 (48.4) & $88(39.1)$ & 0.103 \\
\hline $\mathrm{UA}^{*}$ & $23(14.8)$ & $39(17.3)$ & 0.736 \\
\hline NSTEMI* & $36(23.2)$ & $60(26.7)$ & 0.633 \\
\hline HTN* $^{*}$ & $122(78.7)$ & $164(72.9)$ & 0.368 \\
\hline $\mathrm{DL}^{*}$ & $59(38.1)$ & $86(38.2)$ & 0.735 \\
\hline $\mathrm{DM}^{*}$ & $109(70.3)$ & $167(72.9)$ & 0.583 \\
\hline $\mathrm{HF}^{*}$ & $24(15.5)$ & 25 11.1) & 0.424 \\
\hline Previous $\mathrm{Ml}^{*}$ & $29(18.7)$ & $43(19.2)$ & 0.883 \\
\hline Previous $\mathrm{PCl}^{*}$ & $14(9.0)$ & $11(4.9)$ & 0.267 \\
\hline Previous stroke* & $4(2.6)$ & $1(0.4)$ & 0.197 \\
\hline CKD* & $18(11.6)$ & $18(8.0)$ & 0.471 \\
\hline PAD* & $1(0.6)$ & $5(2.2)$ & 0.475 \\
\hline LVEF\# & $50.7 \pm 9.2$ & $51.4 \pm 9.8$ & 0.469 \\
\hline
\end{tabular}

Figures in the parentheses denote corresponding percentage. *Data were analyzed using Chi-square $\left(\chi^{2}\right)$ Test.

\#Data were analyzed using Unpaired t-Test and were presented as mean \pm SD.

$\begin{array}{lccc}\text { Table II. Distribution of patients by their procedural characteristics } \\ \begin{array}{lccc}\text { Procedural } \\ \text { characteristics }\end{array} & \begin{array}{c}\text { Radial access } \\ (\mathrm{n}=155)\end{array} & \begin{array}{c}\text { Femoral access } \\ (\mathrm{n}=225)\end{array} & \mathrm{p} \text {-value } \\ \text { Contrast volume \# (ml) } & 70 \pm 34 & 72 \pm 40 & 0.267 \\ \text { Procedure time \# (min) } & 25.2 \pm 10.7 & 26.9 \pm 6.8 & 0.735 \\ \text { Fluoroscopy time \# (min) } & 10.7 \pm 5.5 & 9.5 \pm 4.7 & 0.424\end{array}$

\#Data were analyzed using Unpaired t-Test and were presented as mean $\pm \mathrm{SD}$.

\begin{tabular}{lccc} 
Table III. Procedural outcomes in patients undergoing diagnostic CAG \\
\cline { 2 - 3 } $\begin{array}{l}\text { Procedural } \\
\text { outcomes }\end{array}$ & $\begin{array}{c}c \\
\text { Radial access } \\
(\mathrm{n}=155)\end{array}$ & $\begin{array}{c}\text { Femoup } \\
(\mathrm{n}=225)\end{array}$ & p-value \\
$\begin{array}{l}\text { No of patent grafts* } \\
\quad\end{array}$ & $9(5.8)$ & $16(7.1)$ & \\
$\quad \begin{array}{l}\text { No patent graft } \\
1 \text { graft }\end{array}$ & $58(37.4)$ & $78(34.7)$ & \\
2 graft & $59(38.1)$ & $84(37.3)$ & 0.567 \\
3 graft & $28(18.1)$ & $41(18.2)$ & \\
4 graft & $1(0.6)$ & $5(2.2)$ & \\
5 graft & - & $1(0.4)$ & \\
$\begin{array}{l}\text { No of diagnostic } \\
\text { catheters used\# }\end{array}$ & $1.9 \pm 0.7$ & $2.5 \pm 1.3$ & 0.529
\end{tabular}

Figures in the parentheses denote corresponding percentage. *Data were analyzed using Chi-square $\left(\chi^{2}\right)$ Test.

\#Data were analyzed using Unpaired t-Test and were presented as mean $\pm \mathrm{SD}$.

\begin{tabular}{|c|c|c|c|}
\hline \multirow{2}{*}{$\begin{array}{l}\text { Procedural } \\
\text { outcomes in patients } \\
\text { undergoing } \mathrm{PCl}\end{array}$} & \multicolumn{2}{|c|}{ Group } & \multirow[b]{2}{*}{$\mathrm{p}$-value } \\
\hline & $\begin{array}{l}\text { Radial access } \\
\quad(n=155)\end{array}$ & $\begin{array}{c}\text { Femoral access } \\
(n=225)\end{array}$ & \\
\hline \multicolumn{4}{|l|}{ No of lesions treated \# } \\
\hline 1 lesion & $43(79.7)$ & $36(81.4)$ & \multirow{3}{*}{0.583} \\
\hline 2 lesion & $11(20.4)$ & $7(15.9)$ & \\
\hline 3 lesion & - & $1(2.3)$ & \\
\hline \multicolumn{4}{|l|}{ No of stents used \# } \\
\hline 1 stent & $36(66.7)$ & $27(31.4)$ & \multirow{4}{*}{0.194} \\
\hline 2 stent & $14(25.9)$ & $10(22.7)$ & \\
\hline 3 stent & $3(5.6)$ & $3(6.8)$ & \\
\hline 4 stent & - & $1(2.3)$ & \\
\hline Average stent length \#(mm) & $29.8 \pm 15.4$ & $31.2 \pm 16.5$ & 0.689 \\
\hline No of balloons used \# & $1.2 \pm 0.9$ & $1.3 \pm 1.5$ & 0.404 \\
\hline Stent deployment* & $53(96.3)$ & $41(93.2)$ & 0.002 \\
\hline POBA* & $4(7.4)$ & $6(13.6)$ & 0.985 \\
\hline \multicolumn{4}{|l|}{ Target vessel intervention* } \\
\hline SVG & $13(24.1)$ & $13(29.5)$ & 0.590 \\
\hline LCx & $22(38.9)$ & $16(36.4)$ & 0.073 \\
\hline RCA & $19(35.2)$ & $18(40.9)$ & 0.367 \\
\hline LAD & $10(18.5)$ & $3(6.8)$ & 0.026 \\
\hline LIMA & $3(5.6)$ & $3(6.8)$ & 0.891 \\
\hline
\end{tabular}

Figures in the parentheses denote corresponding percentage. *Data were analyzed using Chi-square $\left(\chi^{2}\right)$ Test.

\#Data were analyzed using Unpaired t-Test and were presented as mean \pm SD. 


\begin{tabular}{|c|c|c|c|}
\hline \multirow{2}{*}{$\begin{array}{l}\text { Procedural success } \\
\& \text { MACE in patients } \\
\text { undergoing } \mathrm{PCl}\end{array}$} & \multicolumn{2}{|c|}{ Group } & \multirow[b]{2}{*}{$p$-value } \\
\hline & $\begin{array}{c}\text { Radial access } \\
(\mathrm{n}=155)\end{array}$ & $\begin{array}{c}\text { Femoral access } \\
(n=225)\end{array}$ & \\
\hline Procedure success* $(\%)$ & 96.2 & 96.0 & 0.445 \\
\hline Cross over & $3(5.6)$ & - & 0.194 \\
\hline Vascular complications* & $1(2.3)$ & $6(13.6)$ & 0.003 \\
\hline Access site bleeding & - & $2(4.6)$ & 0.404 \\
\hline Access site haematoma* & $1(2.3)$ & $2(4.6)$ & 0.531 \\
\hline Stroke & 0 & $1(2.3)$ & 0.376 \\
\hline Acute Kidney Injury* & $1(2.3)$ & $2(4.6)$ & 0.590 \\
\hline
\end{tabular}

Figures in the parentheses denote corresponding percentage. *Data were analyzed using Fisher's Exact Test.

\section{DISCUSSION:}

Patients with a history of CABG usually have severe coronary lesions \& are at high risk of cardiovascular events. Although the graft works well right after the bypass surgery, the long-term patency of the graft raises concerns. Saphenous vein graft (SVG) and the internal mammary artery (IMA) are estimated to block up again within 10 years. ${ }^{10} \mathrm{~A}$ second CABG surgery was not suggested because of the serious chest tissue adhesion and the increased risk of death after the surgery. However, PCI is still effective in treating occluded grafts. This retrospective analysis shows that angiography and intervention of postCABG patients can be safely performed via left TRA without significantly altering procedure time and fluoroscopy dose when compared with TFA. TRA is associated with a lower rate of access site-related bleeding.

While there are numerous studies to support the feasibility and safety of TRA of native coronaries, evidence is limited for performing graft angiography. Transradial approach PCI has been increasingly used since its first successful application in 1993 not only because of the easier puncturing and haemostasis, but also for the better survival rate in certain patients. ${ }^{11}$ Han and associates ${ }^{12}$ found similar rates of short-term major adverse cardiac and cerebrovascular events between TRA and TFA (1.5 vs. 5.4, $P=0.479)$ in post-CABG patients undergoing angiography or PCI. Several investigators reported similar short-term death and MACE in post-CABG patients undergoing SVG PCI. ${ }^{13}$ Consistent with these results, the present study showed similar procedural success and short-term clinical outcomes between TRA and TFA.

Access site-related bleeding accounts for approximately $50-80 \%$ of all major bleeding events in patients undergoing PCI. ${ }^{13,14} \mathrm{~A}$ recently published meta-analysis showed that the introduction of TRA decreased the risk of access site related bleeding by $73 \%$. This reduction could lead to better patient outcomes. ${ }^{15}$ More type 2 bleeding was detected in the TFA group than in the TRA group, indicating the benefit of TRA in reducing nuisance bleeding, even under the frequent use of GP IIb/IIIa inhibitors. The rates of access site complications were almost similar between TRA \& TFA (5.1 vs. 7.0, $\mathrm{P}=0.22) .{ }^{16}$

Reduced procedure times are important, not just for patient comfort, but also for improving catheter laboratory efficiency and therefore the cost effectiveness of angiography. Previous studies have already shown that TRA is more cost-effective than TFA due to earlier ambulation and time to discharge. ${ }^{17}$ Our study revealed that the important procedural variable of procedure time, in addition to radiation dose, was unaffected by transradial access route choice for CABG patients, which may result in improved cost-efficiency and patient satisfaction, without affecting patient safety. Fluoroscopy dose remains one of the main safety concerns in coronary angiography, due to the link between radiation exposure and malignancy in operators and patients. ${ }^{18}$ Importantly, we have been able to show that there was no significant difference in radiation dosage between TFA and TRA groups.

Michael and associates demonstrated that TRA resulted in longer procedure times, but no statistically significant increase in patient radiation exposure. Interestingly, in the subgroup of patients who underwent $\mathrm{PCI}$, there was no significant difference between TRA and TFA in terms of procedural time and radiation exposure. ${ }^{19}$ There was no significant crossover rate from radial to femoral route $(3 \%)$. This crossover rate may have been 
partly attributed to trainee involvement as first operators and their underlying inexperience in TRA. This inexperience might be a major contributor to the prolonged procedural times in the TRA group. Our results are comparable with two similar retrospective studies, where there was no difference in procedural time and radiation exposure in patients with coronary grafts undergoing PCI and diagnostic angiography. ${ }^{19}$ Both of these studies involved over 300 patients and had similar crossover rates from radial to femoral route of around $4 \%$. However, the following limitations of study should be considered before generalizing the findings to reference population.

\section{LIMITATIONS:}

The retrospective design was the inherent weakness of our study. The selection of the route was not randomized but was at the doctor's discretion, which might have resulted in selection bias. However, most of the patients' baseline characteristics were similar between the TRA and TFA groups. All the PCIs were conducted only in one hospital, which may restrict the extrapolation of the result to reference population in general.

\section{CONCLUSION:}

The TRA for coronary artery bypass graft intervention is safe and feasible in terms of contrast volume, procedure and fluoroscopy time and other clinical endpoints comparing to femoral access in patients previously under went CABG.

\section{References:}

1. Jolly SS, Yusuf S, Cairns J, Niemelä K, Xavier D, Widimsky $P$ et al. Radial versus femoral access for coronary angiography and intervention in patients with acute coronary syndromes (RIVAL): a randomised, parallel group, multicentre trial. Lancet 2011;377:1409-20.

2. Romagnoli E, Biondi-Zoccai G, Sciahbasi A, Politi L, Rigattieri $S$, Pendenza $G$ et al. Radial versus femoral randomized investigation in ST-segment elevation acute coronary syndrome: the RIFLE-STEACS (Radial Versus Femoral Randomized Investigation in ST-Elevation Acute Coronary Syndrome) study. J Am Coll Cardiol 2012;60: 281-89.

3. Brueck $M$, Bandorski $D$, Kramer $W$, Wieczorek $M$, Holtgen $\mathrm{R}$, Tillmanns $\mathrm{H}$. A randomized comparison of transradial versus transfemoral approach for coronary angiography \& angioplasty. JACC Cardiovasc Interv 2009;2:1047-54.
4. Neill J, Douglas H, Richardson G, Chew EW, Walsh S, Hanratty C. Comparison of radiation dose and the effect of operator experience in femoral and radial arterial access for coronary procedures. Am J Cardiol 2010;106:936-40.

5. Cooper CJ, El-Shiekh RA, Cohen DJ, Blaesing L, Burket MW, Basu A, Moore JA. Effect of transradial access on quality of life and cost of cardiac catheterization: a randomized comparison. Am Heart J 1999;138:430-36.

6. Roussanov O, Wilson SJ, Henley K, Estacio G, Hill J, Dogan $B$, Henley WF, Jarmukli N. Cost-effectiveness of the radial versus femoral artery approach to diagnostic cardiac catheterization. J Invasive Cardiol 2007;19:349-53.

7. Hamon M, Pristipino C, Di Mario C, Nolan J, Ludwig J, Tubaro $M$ et al. Consensus document on the radial approach in percutaneous cardiovascular interventions: position paper by the European Association of Percutaneous Cardiovascular Interventions and Working Groups on Acute Cardiac Care and Thrombosis of the European Society. Euro Intervention 2013;8:1242-51.

8. Frangos $\mathrm{C}$, Nobel $\mathrm{S}$. How to transform you into a radialist: literature review. Cardiovasc Med 2011;14:277-82.

9. Rao SV, Tremmel JA, Gilchrist IC. Best practices for transradial angiography and intervention: a consensus statement from the Society for Cardiovascular Angiography and Intervention's Transradial Working Group. Catheter Cardiovasc Interv 2014;83:228-36.

10. Chew DP, French J, Briffa TG, Hammett CJ, Ellis CJ, Ranasinghe I et al. Acute coronary syndrome care across Australia and New Zealand: the SNAPSHOT ACS study. Med J Aust 2013;199:185-91.

11. Bertrand OF, Rao SV, Pancholy S, Jolly SS, Rodés-Cabau J, Larose $E$, et al. Transradial approach for coronary angiography and interventions: Results of the first international transradial practice survey. JACC CardiovasC Interv 2010;3:1022-31.

12. Han H, Zhou Y, Ma H, Liu Y, Shi D, Zhao Y, et al. Safety and feasibility of transradial approach for coronary bypass graft angiography and intervention. Angiology 2012;63: 103-8.

13. Amoroso G, Kiemeneij F. Transradial access for primary percutaneous coronary intervention: The next standard of care? Heart 2010;96:1341-4.

14. Burzotta F, Trani C, Hamon M, Amoroso G, Kiemeneij F. Transradial approach for coronary angiography and interventions in patients with coronary bypass grafts: Tips and tricks. Catheter Cardiovasc Interv 2008;72:263-72.

15. Mehran R, Rao SV, Bhatt DL, Gibson CM, Caixeta A, Eikelboom J, et al. Standardized bleeding definitions for cardiovascular clinical trials: A consensus report from the Bleeding Academic Research Consortium. Circulation 2011;123:2736-47.

16. Goldman S, Zadina K, Moritz T, Ovitt T, Sethi G, Copeland JG, et al. Long-term patency of saphenous vein and left internal mammary artery grafts after coronary artery bypass surgery: Results from a department of veterans affairs cooperative study. J Am Coll Cardiol 2004;44: 2149-56. 
17. Verheul HA, Moulijn AC, Hondema S, Schouwink M, Dunning AJ. Late results of 200 repeat coronary artery bypass operations. Am J Cardiol 1991;67:24-30.

18. Bundhoo SS, Earp E, Ivanauskiene T, Kunadian V, Freeman $P$, Edwards $R$, et al. Saphenous vein graft percutaneous coronary intervention via radial artery access: Safe and effective with reduced hospital length of stay. Am Heart J 2012;164:468-72.
19. Michael TT, Alomar M, Papayannis A, Mogabgab O, Patel VG, Rangan BV et al. A randomized comparison of the transradial and transfemoral approaches for coronary artery bypass graft angiography and intervention (the RADIAL-CABG trial). JACC Cardiovasc Interv 2013;6: 1138-44. 